Session 2432

\title{
Breadth and Unity: A Revised Electrical Engineering Curriculum at Princeton University
}

\author{
J.C. Sturm and A. Wolfe \\ Department of Electrical Engineering \\ Princeton University, Princeton, NJ 08544 \\ Ph: 609-258-5610, Fax:-6279 sturm@ee.princeton.edu
}

\begin{abstract}
The Electrical Engineering department at Princeton University has completely revised its undergraduate program. This paper will discuss the forces driving the change and the philosophy behind the reforms, and then give an overview of the changes in both the sophomore and upperclass years. The main themes of the reforms have been to encourage breadth (at the expense of depth if necessary) and to stress the relationship between academic topics and products.
\end{abstract}

\section{Introduction}

The Electrical Engineering Department at Princeton University consists of 25 full-time faculty members (all of whom teach undergraduates), approximately 110 undergraduates (divided over sophomore, junior, and senior years) and about 100 graduate students, mostly at the Ph.D. level. From 1992 to 1994, the department undertook a wide ranging evaluation and reform of its undergraduate program. The evaluation led to a complete revision of its undergraduate courses. This paper will discuss the motivation which led to the evaluation, the guiding philosophy of the reforms, and then focus on the details of the reforms for both sophomore and upperclass years. Finally, outstanding issues will be mentioned.

\section{Motivating Factors and Long Term Goals}

Prior to this revision, the basic undergraduate EE program at Princeton had not changed for some 30 years. In the late 80's and early 90's, several factors combined to lead the department to review its program. The first was the perceived changing nature of the incoming students. While equally as bright as their predecessors of 20 years ago, the students now seem to have less of an inherent feel for engineering and less of an idea of what it is that engineers really do. This had led to a lower interest in course material, especially in introductory level courses. While the first issue may be part of a national trend, the second issue was more of a local concern. Our undergraduate program had gravitated over the years to mirror our graduate program, with the end result that many of our students were leaving after four years with a degree of expertise almost that expected of a master's student, but with an extreme lack of breadth. Third, from the late 80 's to early 90 s the undergraduate enrollment in the EE department had dropped by nearly $40 \%$, an effect which was not reflected in the engineering school as a whole. Finally, there was a desire to look forward and ask what the needs of future engineers would be. How could we best prepare our students to be future leaders in the field? 
The freshman year at Princeton is generic for all engineers, and without advanced placement typically consists on the technical side of one year of physics, one year of calculus, one semester of chemistry, and one semester of programming. A separate engineering school committee is addressing non-traditional freshman years; the EE department alone went ahead with reforms for sophomore through senior years. In the past, all EE sophomores would take an introductory course on circuits, and then pick two of several electives introducing them to various academic fields of specialization, one of which they would pick for concentration. These fields were the information science and system area, computer engineering, and the solid state area. This method had two drawbacks. First, in deciding what electives to take, students were essentially choosing their track within EE, in many cases before they had taken any EE courses! Coupled with the students increasing lack of familiarity with EE before arriving at Princeton, this naturally led to uninformed decisions. Second, these elective courses often tended to be taught as an introduction to a field for future specialists in that field, rather than a broad survey. That is, the courses tended to develop theories and mathematical methods to be used over the next few years, but did not develop the connection between this field and products or systems. Such courses tended to scare away students without an expressed interest in the area, discouraging breadth since these courses were prerequisites for any future work in that part of the department.

Because of the rapid change of technology, and the increasing importance of interdisciplinary work both within EE as well as between $\mathrm{EE}$ and other fields, the EE department decided that our old structure, which encouraged specialization at the expense of breadth, was a disservice to most of our students. Students who are interested in specialization can go to graduate school, but they have only one opportunity to learn the basics over a wide area. Therefore a fundamental goal of our reforms was to encourage and even require more breadth across EE than had been the practice in the past, even if it came at the expense of depth. Second, it was decided that we should do a better job at showing students what real EE's do, as opposed to just what professors do, to help the students develop the "big picture" that many are seeking. This involves stressing the connection between EE tools and methods (around which courses and research are often organized) with products, which often represent the real interest of students.

For several reasons it was also decided that the four-year degree (as opposed to a five-year program) should remain the focus of our undergraduate program. Although five years would be useful in allowing us to cover more material in specialized areas, we decided that students desiring a fifth year of instruction would probably benefit more by experiencing life at a different institution. Furthermore, many of our undergraduates immediately go on to careers other than engineering, such as medicine, business, etc, so that a fifth technical year would be of little added benefit. Financial considerations and a desire to remain consistent with the rest of the university were also factors behind this decision.

The main curriculum reforms will now be discussed, starting with the sophomore year and then the upperclass years. 


\section{Sophomore Year}

The sophomore year sets the tone of the revised curriculum most strongly. Our sophomores are now required to take a unified curriculum consisting of two core EE courses each semester. The courses give the students an overview of EE and how products are designed on various levels (component, circuit, logic, control, system, etc). Each of those levels is then developed in depth over the year. These courses are designed to give a student an understanding of the issues in the different fields across EE, even if he or she takes no more courses in that field. These four courses are EE 201 (fall), Introduction to Electrical Systems and Signals; EE 203 (fall), Electrical Circuits; EE 206 (spring), Introduction to Logic Design; and EE 208 (spring), Integrated Circuits: Practice and Principles. The Systems and Signals course is a top-down view of electrical systems that process information-carrying signals. Concepts such as analog, digital, frequency content, modulation, feedback, etc, are introduced not in an abstract way but through the direct examination of various systems (such as a CD player or modem). Students learn that one needs boxes such as amplifiers or D/A converters, etc, but do not look inside these boxes. The circuits course is a first exposure to the physical side of EE, and complements the system course well as the students now clearly see the need for an amplifier (and the need for linearity), and can begin to draw the link between physical limitations and system performance limitations. Besides circuits, the course also introduces various kinds of transducers between the electricity and the rest of the physical world.

The digital logic course introduces digital logic gates and their application, from basic memory elements to basic computer organization. Transistors are introduced simply on the level of ideal switches, which sets up the motivation for the accompanying course on integrated circuits. In this course semiconductors and device operation are explained on the simplest level possible, application to very simple circuits is stressed, and all students fabricate their own microchip by themselves in an integrated circuit fabrication lab. The goal of the course is not for students to become an expert in transistor design, but rather to see that both the performance of digital systems (e.g. power-delay product) and of analog systems (e.g. gain-bandwidth product) depends on physical quantities (e.g. a linewidth on a chip), and to understand the power of microfabrication and integration.

Because these courses are specifically designed to give our students a wide background, as opposed to introducing tools for later specialty courses, we hope to give them a big picture of EE. The ability to see how pieces fit together to make products and systems will hopefully increase their motivation to pursue future EE courses. Students will also be better prepared for their decision in the junior year to pick an area for specialization. A final benefit of the unified sophomore curriculum is that our juniors now have a uniform preparation across the department. This made it possible to greatly reduce the depth of the upperclass prerequisite tree, as will be discussed in the next section.

\section{Upperclass Years}

There were four main upperclass reforms. The first was a flattening of the prerequisite tree to encourage breadth. It is now at most only two deep (after the sophomore courses) (Fig. 1), as opposed to four previously. This was made possible by the new uniform preparation of the 
sophomores, and also by the rearrangement of material in the upperclass courses. The consequence of this revision is that it is now possible to get to courses at the end of the tree (which are often the most interesting) in more than one area of specialization. Previously, the long prerequisite structure made it prohibitive for students to take courses outside their narrow path.

The second upperclass reform was a redefinition of the area of depth. Instead of the previous three traditional rigorously defined areas (Information and Systems, Computer Engineering, and Solid State), there are now 14 overlapping "topical areas," many of which are interdisciplinary (e.g. "digital video and graphics") (Fig. 2). This change was made for two reasons. First, because many important technological areas are interdisciplinary, and not addressed in a usual academic structure, students can now directly focus on one of these areas, as opposed to having to approach it from one end or the other. The second reason was to increase the perception of the program as interesting to students. Many students who would not be attracted by the idea of studying something abstract such as "Solid State" or "Computer Engineering" are attracted by topics such as "Microelectronics" or "Optical Communication". To fulfill the requirements of one area of concentration, a student must take one or two required courses for each concentration, followed by some electives (to total three courses together). In some concentrations the courses are contained wholly within a traditional academic area (e.g. signals and systems), while the courses for the more interdisciplinary topics cover two or more areas. It should be noted that there is substantial overlap with other departments (e.g. the robotics concentration). Upperclass courses from every engineering department as well as from math and physics are on the list of courses for at least one concentration. That is, these courses in other departments can be counted explicitly towards a student's EE concentration requirement as long as they are a coherent part of the topic of concentration. Breadth across EE is insured by requiring that students take at least one upperclass course from at least two different branches of the traditional academic tree (Fig. 1), on top of the wide background that all EE's get in the sophomore year.

For a third upperclass reform, the previously traditional analog electronics course for juniors has been made an elective. This was done because fewer and fewer EE's will actually design an analog circuit in their career, and the basic idea that an amplifier can be made from transistors has already been covered in the sophomore year. Signal processing in a general sense is still a vital skill, so a new course "Signal Processing and Circuits" is now required. This course shows how signal processing problems (e.g. a filter) may be implemented both in analog and digital formats, both in lecture and in lab.

Finally, the second and last required upperclass course is a new laboratory design course. Juniors work in teams to design and build a system to meet a specified performance goal. There are no formal lectures, tests, or homework assignments in this course, just a series of long term laboratory projects of increasing complexity, which in the end are all combined to create a larger system. The skills covered include analog and digital electronics, microprocessor programming and interfacing, and control. This past year the ultimate goal was a car (using a supplied kit of mechanical parts) which could follow a curved white line painted on the floor. Although this course is the one most unlike any of the traditional EE courses at Princeton, it is the one which probably gives students the experience most like that of an engineer in industry. 


\section{Outstanding Issues}

There are at least two areas in which substantial further progress is required. The first is in further showing our students what engineers do in the real world through industrial exposure, beyond having a professor explain in class how things work. For example, we could regularly have industrial speakers visit and speak on an undergraduate level. Special lectures along these lines in the past have been only poorly attended, however. There are many industrial labs in the local area to visit, but trips in the past have also been poorly attended, despite quite a bit of publicity. Many students initially intend to go, but at the last minute decide they have too many other pressing assignments to allow them to take the afternoon off. Those that do go find the experience very valuable, however. Further innovative thinking in this area is required.

The second area which requires further attention is that of independent work. While a senior thesis or independent project is not required, about $70 \%$ of our seniors and a substantial number of juniors indeed to elect at least one semester of independent work, and receive course credit for their effort. Most of these projects, especially those that require space or hardware, are offshoots of faculty research and are performed in the research labs alongside graduate students. While such an exposure to research is indeed valuable in many cases, there is at present very little space or hardware available for students with their own ideas or for those who just want to tinker. The addition of space and resources for unstructured independent work, and work that is truly "independent" of existing research efforts, is needed to fill this void.

\section{Summary}

The recent reforms in both the sophomore and upperclass years in EE education at Princeton University have been described. The two driving features of the reforms have been breadth instead of specialization and to reinforce the connection between the coursework and the real EE world. The enrollment in the EE department has recovered to levels much higher than a few years ago, although still somewhat lower than the peak some 10 years ago. The new curriculum has also been strongly endorsed by ABET in their initial informal feedback after a recent accreditation visit. Further work is needed to strengthen the industrial exposure of students, and to develop resources for independent work. 


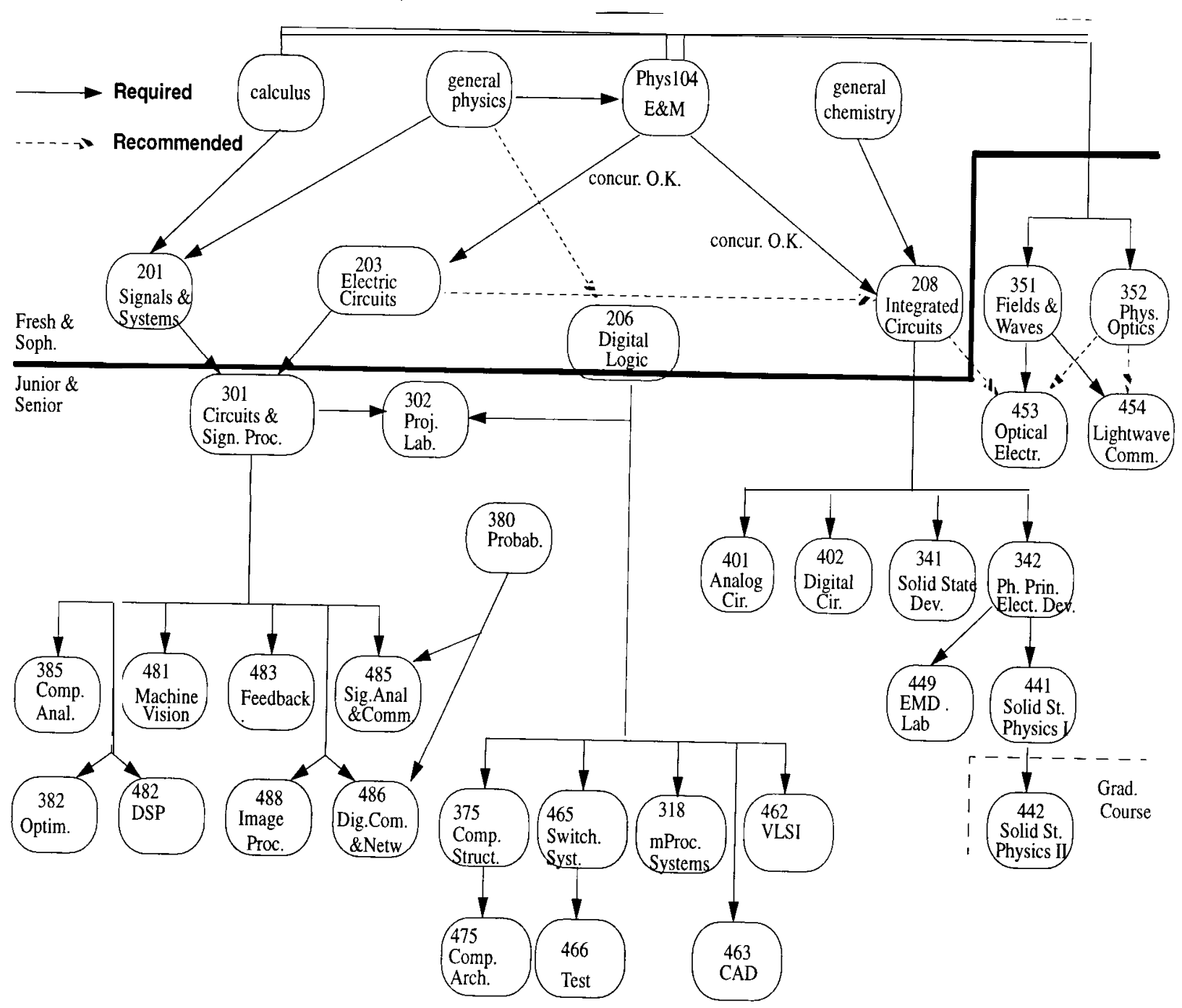

Figure 1. Prerequisite tree for Electrical Engineering, showing both sophomore (200 level) and upperclass (300 and 400 level) years. 


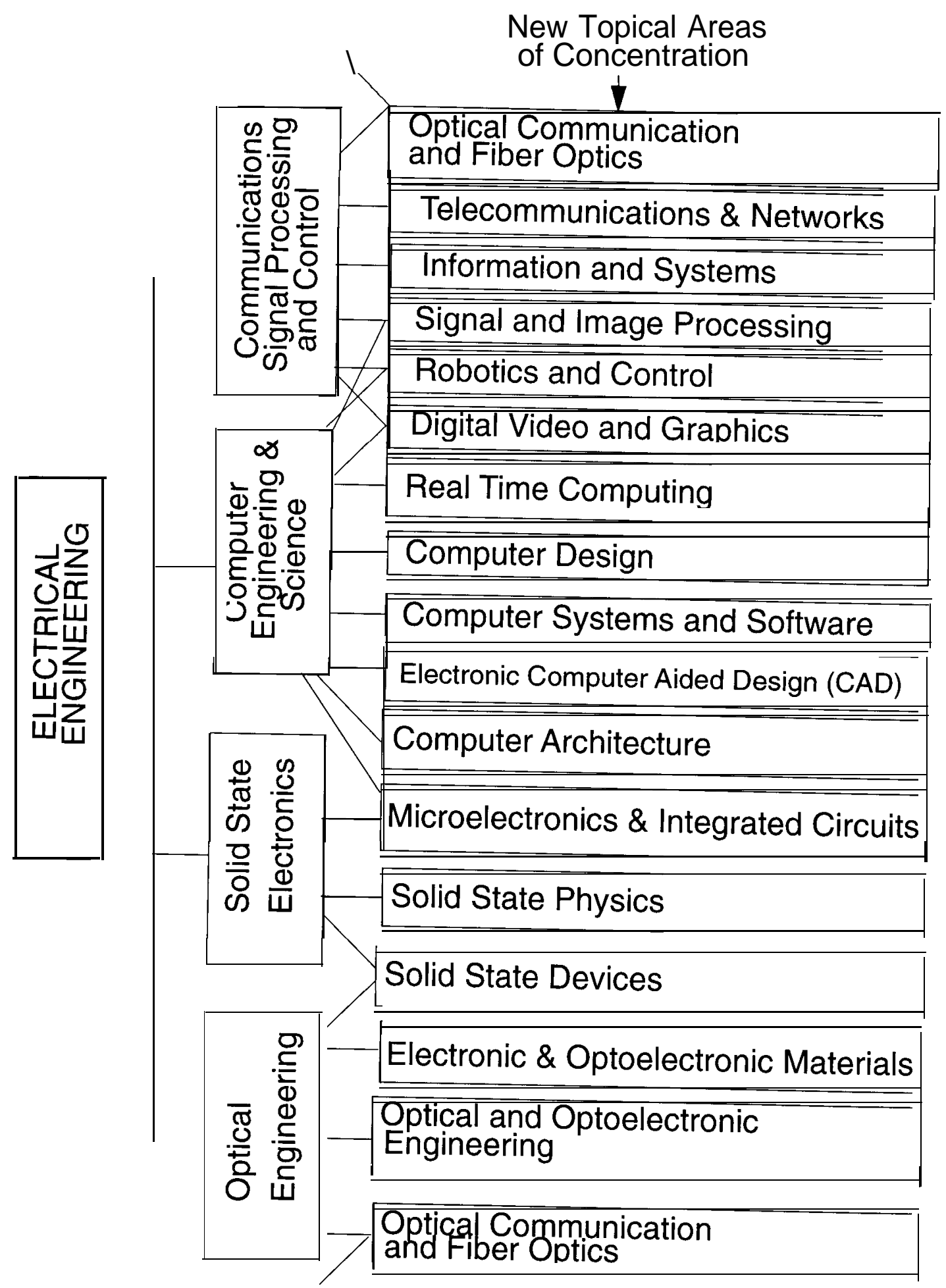

Figure 2. Topical areas of concentration and their relation with traditional EE academic areas. 